\title{
Análise de Compatibilidade Empresa/Mercados de Exportação COM Base na Comparação dos Índices DE BELA BalassA*
}

\author{
ANALYSIS OF THE COMPATIBILITY BETWEEN THE COMPANY \\ AND ITS EXTERNAL MARKETS BASED ON BELA BALASSA INDEX
}

JOSÉ MANUEL BAPTISTA MEIRELES DE SOUSA Doutor em Administração e Comércio Exterior, pela faculdade de Ciências econômicas e Empresariais da Universidade de Extremadura,

Espanha. Professor na Universidade Anhembi Morumbi. Rua Pedro Badra, 51 - São Paulo - SP - CEP 04348-090

E-mail: jose-meireles@uol.com.br

* O autor agradece ao professor Geraldo Canto pelos seus comentário e sugestões na revisão deste artigo. 


\section{RESUMO}

As pequenas e médias empresas brasileiras que representam peso relevante no tecido empresarial têm sido objeto de políticas, tendo como finalidade aumentar a sua participação no comércio exterior. Nem sempre os produtores/exportadores conseguem associar a atratividade de determinado mercado à compatibilidade com a sua empresa. Assim, em face da crescente necessidade da disponibilização de ferramentas que permitam auxiliar os potenciais exportadores no processo de tomada de decisão sobre quais os mercados devem explorar, sugere este artigo uma metodologia que visa a hierarquizar mercados pela sua compatibilidade, em função quer da tradição exportadora do Brasil, quer das vantagens comparativas reveladas por determinado setor de atividade e/ou produto.

\section{PALAVRAS-CHAVE}

Pequenas e médias empresas; Internacionalização; Vantagens comparativas; Tradição exportadora.

\section{ABSTRACT}

Small medium companies represent an important share in the total of the Brazilian companies but have small weight in the external trade balance although at present are being stimulated trough appropriate official politics to increase its participation in the foreign trade. Not always the exporting producers associate the attractiveness of a market with the compatibility towards its company. Then, in view to the increasing necessity of tools that can assist the decision making process, related to the election of external markets we suggest in this article a methodology that aims to select a market, according to its compatibility with the exporting company, measured by the exporting tradition of Brazil in that industry, and the comparative advantages of that product. 


\section{KEYWORDS}

Small and medium enterprises; Internationalization; Comparative advantages; Exporting tradition.

\section{INTRODUÇ ÃO}

O começo deste novo milênio tem sido caracterizado por uma série de circunstâncias atípicas, que têm mudado a forma de atuação quer de políticos e empresários, quer, principalmente, do cidadão comum. O trilho que vinha sendo percorrido desde o final da Segunda Guerra e os ideários que vinham sendo perseguidos e trabalhados deixaram no final do século passado de servir de referência à grande maioria, que de confusa tem gradativamente passado a expectante, até poder desejavelmente definir o seu rumo. A queda do muro de Berlim, o desaparecimento da influência da URSS, as crises petrolíferas, a crise asiática ou a crise da Rússia contaminaram países de outros continentes (MAIA, 2003) e fizeram se repensarem os modelos de desenvolvimento. Nos dias de hoje, o II de setembro, a guerra no Iraque, a crise Israel-Palestina, o II de março ou mesmo os fundamentalismos religiosos certamente condicionarão as estratégias futuras que nortearão desde políticos até cidadãos em geral, interferindo no processo decisório empresarial.

A realidade presente, chamada de era da informação, além da situação caótica em que vivemos, na qual a imprevisibilidade é regra geral e a velocidade do imprevisto tem crescido, faz da rapidez arma fundamental e decisiva para combater a inércia, quer da estática conservadora empresarial, quer mesmo de muitas dinâmicas empresariais em curso. Ou seja, as ações que produzem efeito são tão mais eficazes quanto mais rapidamente são tomadas, tornando a informação recurso fundamental das empresas, que ficam condicionadas não só às suas capacidades de observação e captura da informação, mas sobretudo às suas capacidades de torná-la disponível e útil à condução dos processos. Cabe aos empresários desenvolver as atividades de amanhã e utilizar essa gama enorme de informação para prolongar a capacidade inovadora, melhorar a competitividade e criar mais empregos. ${ }^{1}$ De nada servirá para alguém ter a capacidade de fazer, se não puder levá-la à prática. Resulta assim que o conhecimento e a cultura têm de caminhar lado a lado com a estrutura, pois de nada serve ter muito conhecimento difundido, se a estrutura não o absorver.

I Comunicação da Comissão Européia, de 4 de fevereiro de 2000 , Estratégias de criação de empregos na sociedade da informação. 
Os estados socioeconômicos atual e futuro serão condicionados não só pelo que se fizer hoje, mas fundamentalmente pela possibilidade de os acontecimentos serem acompanhados, com alterações político-estratégicas que permitam a todo o momento moldar o atual ao imprevisto, sem provocar reações ou modificações profundas, no status quo, tornando-se essencial efetuar análise da competitividade empresarial em face da dinâmica do novo modelo de desenvolvimento, ao serem estabelecidas políticas que almejem o desenvolvimento sustentável das empresas no estado atual da economia.

A importância das pequenas e médias empresas (PMEs) é ressaltada em muitos estudos internacionais (NOTHDURFT, I992), as políticas públicas de inovação das PMEs são vistas como fato importante em todo o mundo (ESHIMA, 2003), o crescimento das PMEs contribui para o aumento do bem-estar por meio da criação de novos negócios e empregos (ACS, I999) e a promoção das capacidades exportadoras é atualmente um dos eixos da política industrial em muitos países (HOGAN, I99I). "As pequenas e médias empresas, constituem a força motriz do desenvolvimento econômico em geral e do desenvolvimento industrial em particular" (KAPLINSKY e MORRIS, 200I:2), "pois nelas sobressaem as características da especialização, flexibilidade, facilidade de interação interempresarial e estruturas menos hierarquizadas" (LEMOS, 2000:2), necessárias à implementação do novo modelo de desenvolvimento sustentável na moderna sociedade da informação.

Este artigo visa ao estabelecimento de uma metodologia que possa ser adotada quer pelas empresas industriais exportadoras de pequena dimensão quando pretendam desenvolver mercados alternativos com base nas suas estratégias de internacionalização, quer pelo setor público ao direcionar as suas políticas comerciais. O estudo terá como referência a forma como a ampliação da União Européia - de 15 para 25 países - poderá favorecer empresas brasileiras de pequena dimensão e contribuir para o seu desenvolvimento sustentável. Serão analisadas as evoluções das relações comerciais entre o Brasil e a União Européia, quanto ao ponto de vista de penetração de mercados, integração e especialização, utilizando neste processo analítico os índices de Bela Balassa - das Vantagens Comparativas Reveladas - e os indicadores de cobertura e de grau de abertura total. Assim, numa perspectiva de capacidade de resposta do ponto de vista dinâmico e de agilidade, estudar-se-ão os novos mercados da União Européia com processos de integração mais avançados, e os produtos nos quais se revelem vantagens comparativas mais significativas, estabelecendo balanço entre as políticas de integração e a tradição exportadora dos setores mais significativos. Essa análise terá, assim, o objetivo de proporcionar ferramenta validada aos executantes de políticas comerciais, ${ }^{2}$ de estratégias de internacionalização empresariais ou de políticas de desenvolvimento, para empresas de pequena e média dimensão. 


\section{REFERENCIAL TEÓRICO}

Na nova realidade dos mercados, assiste-se a uma crescente integração - contratada ou imposta -, que tem condicionado o desenvolvimento empresarial, fato que tem sido importante aspecto analisado pelas novas teorias do comércio internacional (BALASSA, I964; BERGSTERN, 2000), e considerado também em estudos nos quais são analisadas as influências das vantagens comparativas no desenvolvimento do comércio intraindustrial (GRUBEL e LLOYD, I975; KRUGMAN, I980; LANCASTER, I980; HELPMAN, I98I; GREENAWAY, 2003) ou, mais recentemente, por Hunt (2000) pela teoria da vantagem em recursos (Resource Advantage Theory).

Nos mercados atuais de crescente integração torna-se fundamental o estudo da especialização internacional em face das teorias de comércio internacional, pois, se nas teorias clássicas os modelos previam mercados em concorrência perfeita e não evolução das aptidões, nas novas teorias "a especialização pela dotação de fatores serve de explicação ao desenvolvimento" (MEDEIROS, 2003:93).

O desenvolvimento dos mercados decorrente das políticas de integração econômica em curso afeta o desenvolvimento das empresas, facilitando a mobilidade de recursos, o acesso a novos produtos pelos consumidores - que todavia são condicionados pela comunicação imperfeita - e influenciando as ofertas das empresas, que passam a ter vantagens comparativas por meio de seus recursos com reflexo em produções eficientes e eficazes das suas ofertas (HUNT, 2000).

Ampliando-se a noção de recursos, além dos clássicos fatores tangíveis, também há fatores intangíveis, entre eles os organizacionais (HUNT, 2002:22), admitem-se algumas premissas como a heterogeneidade das demandas nos mercados, a heterogeneidade dos recursos e a sua imperfeita imobilidade, contrariando as teorias clássicas de concorrência perfeita. A orientação ao mercado das empresas, exercida pelo controle dos canais de comercialização, passa a ser considerada como recurso intangível fundamental (HUNT e MORGAN, I995), pois, ao fornecer rapidamente informação, possibilitará à empresa produzir ofertas adaptadas aos diferentes segmentos de mercado, permitindo respostas rápidas às suas solicitações.

No Brasil, temos assistido nos últimos anos à perda do controle de empresas brasileiras sobre os canais de exportação (PINHEIRO, 2000). Crê-se que esteja na hora de o maior setor empresarial brasileiro - o setor das empresas de pequena e média dimensão ${ }^{3}$ - se afirmar como tal, aproveitando as oportunidades que são disponibilizadas pela crescente abertura de mercados, pois a sua capacidade competitiva determinará, em grande medida, o êxito empresarial em um processo de integração (FERRARO e GATTO, I993, I995; GATTO, I994).

3 Sobre classificação de empresas de pequena e média dimensão, consultar

$<$ www.bndes.gov.br/clientes/porte/porte.asp >. 
A diferença entre aproveitar uma oportunidade - exportação pontual ou indireta - e a internacionalização - estratégia de desenvolvimento empresarial - caracteriza por esta última a sustentabilidade do desenvolvimento das empresas ao se relacionarem com mercados exteriores. Todavia "os canais de exportação poderão ser entendidos como uma função multivariada em que o exercício de seu controle é o contradomínio, enquanto as partes que o compõem representam o domínio existindo assim uma relação direta entre o grau de controle do canal de comercialização e o desempenho do exportador do país/região" (GUIMARÃES, 2002:45I). Cabe assim analisar a forma como o recurso "controle de mercado" se relaciona com a atividade exportadora da empresa num processo de integração econômica.

\section{O ESTADO DA ARTE}

O ciclo de abertura do Brasil ao comércio internacional, iniciado no começo dos anos 9o, não teve continuidade, sobretudo na forma qualitativa pela agregação de valor, tendo se diversificado em comercialização de produtos naturais, e não penetrado de forma significativa em produtos manufaturados, o que é confirmado pela fraca participação do Brasil no comércio mundial Gráfico I.

A abertura de mercados e a desvalorização da moeda não tiveram o efeito desejado na alavancagem das exportações de empresas brasileiras, muito embora a participação das exportações no valor da produção tenha aumentado nos últimos anos, tanto no total da indústria quanto na maioria dos setores. ${ }^{4}$ Fato é que a grande maioria dos produtos do agronegócio (grãos) e minérios - alicerces da exportação brasileira - é controlada de fora para dentro, pois é cotada em mercados internacionais, e os produtos manufaturados que aumentam a sua participação no comércio exterior - Gráfico 2 - estão gradualmente passando para o controle da exportação de corporações com matriz no exterior ou empresas de trading ${ }^{5}$ estrangeiras - Quadro I.

As empresas de pequena dimensão, na maioria dos casos, vêem os produtos de sua fabricação sendo comprados por tradings estrangeiras ou grandes empresas locais, que os comercializam nos mercados externos, ou mesmo estão sendo terceirizadas no que se refere à sua produção, proporcionando emprego (muitas vezes temporariamente), mas não usufruindo os efetivos ganhos dos

4 Disponível em: <www.funcex.com.br>. Acesso em: I7 de maio de 2004.

5 Trading - empresa de intermediação que comercializa em mercados internacionais produtos fabricados por empresas produtoras, gerenciando todo o processo logístico. 
seus produtos. Perdem, assim, o controle da comercialização da sua produção, aumentando a vulnerabilidade e comprometendo a sua sobrevivência.

Efetivamente a falta de penetração comercial nos mercados internacionais, por um lado, e o maior controle da exportação de produtos de maior valor agregado, por outro, conforme o Gráfico 2, que relaciona a evolução de produtos manufaturados - com maior valor agregado - com a origem de propriedade das firmas - nacionais ou estrangeiras (PINHEIRO, 2000), permitem verificar a grande dependência e a sua maior conseqüência: a falta de controle dos canais de comercialização, cuja influência no emprego é significativa.

\section{GRÁFICO I}

\section{A PARTICIPAÇÃO \% DO BRASIL NO COMÉRCIO MUNDIAL}

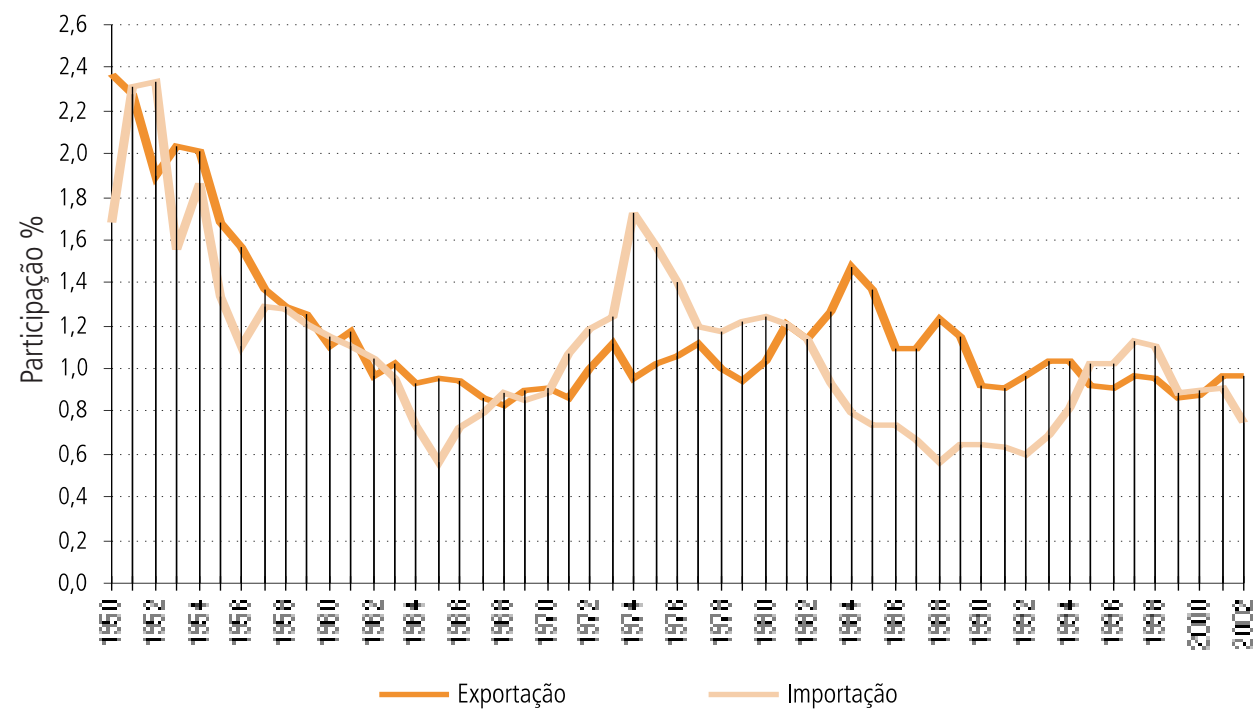

Fonte: Exportações brasileiras: Siscomex e Secex; Importações brasileiras: Siscomex e MF/SRF. 
- ANÁLISE DE COMPATIBILIDADE EMPRESA/MERCADOS DE EXPORTAÇÃO

COM BASE NA COMPARAÇÃO DOS ÍNDICES DE BELA BALASSA •

- JOSÉ MANUEL BAPTISTA MEIRELES DE SOUSA •

\section{GRÁFICO 2}

EXPORTAÇÃO BRASILEIRA POR FATOR AGREGADO - I964 A 2004 (JANEIRO/FEVEREIRO) PARTICIPAÇÃO \% SOBRE O TOTAL GERAL

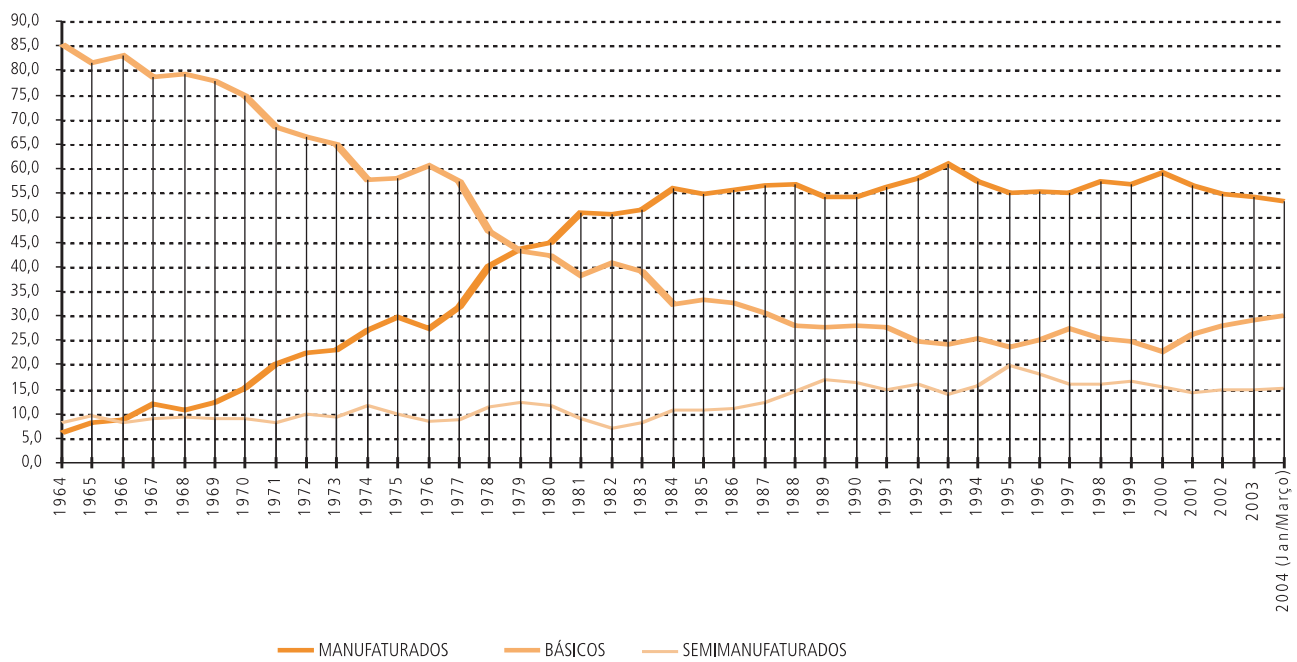

Fonte: SECEX/DEPLA.

\section{QUADRO I}

EXPORTAÇÃO DE MANUFATURADOSa (EM \%) POR ORIGEM DE PROPRIEDADE I990 - I995 - I999

\begin{tabular}{l|r|r|c}
\hline \multicolumn{1}{c|}{ Firmas } & 1990 & 1995 & 1999 \\
\hline Estrangeiras $^{\mathbf{b}}$ & 30,81 & 38,10 & 38,28 \\
\hline Nacionais & 69,19 & 61,90 & 61,72 \\
\hline TOTAIS & 100 & 100 & 100 \\
\hline
\end{tabular}

a - classificação Secex

b - firmas controladas por não residentes

Fonte: PINHEIRO e MOREIRA, 2000.

Deduzem-se, assim, dois tipos de fatores de influência perversa no desenvolvimento sustentado das indústrias que procuram esse objetivo em mercados externos: 1 o controle do mercado pela empresa produtora e 2 a origem de propriedade da empresa. 
As médias e pequenas empresas estão crescendo sua participação como empresas exportadoras - Quadro 2 - apresentando, no entanto, maior vulnerabilidade, principalmente no que respeita ao ponto $\mathbf{1}$, anteriormente referido, pelo que deverão ser objeto de políticas específicas no que se refere aos apoios à exportação.

\section{QUADRO 2}

NÚMERO DE EMPRESAS EXPORTADORAS POR TAMANHO DA FIRMA I997/200I

\begin{tabular}{l|r|r|r|r|r}
\hline \multicolumn{1}{|c}{} & \multicolumn{1}{r}{ em no absoluto } \\
\hline Tamanho da firma & 1997 & 1998 & 1999 & 2000 & 2001 \\
\hline Micro & 5.286 & 5.553 & 6.343 & 6.513 & 6.208 \\
\hline Pequena & 3.992 & 4.114 & 4.442 & 4.784 & 4.866 \\
\hline Média & 3.022 & 2.978 & 3.086 & 3.226 & 3.294 \\
\hline Grande & 1.197 & 1.130 & 1.125 & 1.160 & 1.142 \\
\hline Não classificada & 353 & 191 & 172 & 333 & 1.311 \\
\hline TOTAL & 13.850 & 13.964 & 15.168 & 16.016 & 16.821 \\
\hline
\end{tabular}

Fonte: Secex/MDIC, Rais/MTE (I997, I998, I999, 2000, 200I)

IBGE (cadastro I999 e PIA - 2000).

\section{INDICADORES DE INTEGRAÇÃO ECONÔMICA}

Segundo Bela Balassa, ${ }^{6}$ conhecido principalmente na literatura econômica pelo chamado índice de Balassa, o fenômeno da integração econômica desenvolve-se em cinco fases sucessivas e de progressiva integração: ${ }^{7}$

I) Zona de comércio livre: zonas de integração em que são eliminados reciprocamente os direitos aduaneiros.

2) União aduaneira: acrescenta ao caso anterior a adoção de uma tarifa aduaneira comum em relação a países terceiros.

6 Bela Balassa - economista húngaro que caracterizou a integração econômica como um processo gradual $<$ http://.iceg.org/author.cfm?ID=5> e <http://www.banrep.gov.co/balaavirtual/boleti5/bolı6/result.htm>.

7 A União Européia apresenta, nesta perspectiva, diferentes níveis de integração, sendo o mais avançado a união monetária. 
3) Mercado comum: além da livre circulação de mercadorias, pressupõe a livre circulação de pessoas e capitais.

4) União econômica: trata-se de um mercado comum com políticas macroeconômicas comuns.

5) União monetária: além dos pressupostos da União Econômica, exige uma unificação da moeda, união financeira e social em que a execução das políticas está a cargo de instituições supranacionais que gozam de poder coercivo.

Uma maior integração conduz, em regra, a um maior grau de abertura das economias ante o exterior, "dependendo de numerosos fatores, envolvendo, com certeza, o elemento doutrinário entre o livre-cambismo e o protecionismo" (MEDEIROS 2003:I02), que pode ser apresentado de acordo com a seguinte equação, indicativa do "Grau de Abertura Total (GAT)":

$$
\text { GAT }=\frac{\text { Exportação + Importação }}{\text { PIB }}
$$

O indice geral de Bela Balassa - IBB - exprime a relação entre o saldo da balança comercial e as trocas comerciais globais. Valores próximos de \pm I indicam uma especialização unívoca, respectivamente, exportadora e importadora:

$$
\mathrm{IBB}=\frac{X-M}{X+M}
$$

em que:

$\mathrm{X}$ - exportações totais

$\mathrm{M}$ - importações totais

Quando o índice se aproxima de (+I), ou seja, [Xi-Mi próximo de Xi+Mi], representa um grande grau de especialização intersetorial (exportações do produto i muito importantes e importações pouco significativas). No caso de o índice apresentar valores próximos de (-I), o país em questão tem fraca especialização no produto i e Xi tenderá para zero.

$\mathrm{O}$ indice das vantagens comparativas relevadas de Balassa, $\mathrm{IVCR}_{\mathrm{i}}$, é definido do seguinte modo:

em que:

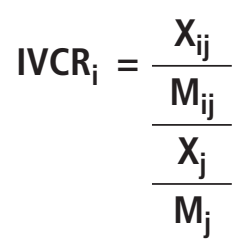


Xij - exportações do produto i pelo país j

$\mathrm{Xj}$ - exportações totais do país $\mathrm{j}$

Mij - importações do produto i efetuadas pelo país j

$\mathrm{Mj}$ - importações totais do país j

O país j terá vantagens comparativas no que diz respeito ao produto i quando a taxa de cobertura Xij/Mij for superior à taxa de cobertura global $(\mathrm{Xj} / \mathrm{Mj})$, ou seja, quando o índice apresentar valor > I.

Balassa nos sugere outra formulação do índice de vantagens comparativas - $\operatorname{IVCR}_{\mathrm{i}(2)}$ :

$$
\operatorname{IVCR}_{i(2)}=\left[\frac{X_{i}-M_{i}}{X_{i}+M_{i}}-\frac{\sum X_{i}-M_{i}}{\sum X_{i}+M_{i}}\right] \times 100
$$

em que:

$\mathrm{Xi}$ - valor da exportação de produtos (i)

$\mathrm{Mi}$ - valor da importação de produtos (i)

Dessa forma é demonstrada a situação relativa em que se encontra em cada ano o produto ou grupo de produtos examinados (i) relativamente ao correspondente total do país. Se a diferença relativa entre exportações e importações coincidir com o comércio total, o índice será igual a zero; no caso de ser maior, o índice será positivo (esse produto revela uma vantagem comparativa); e em caso contrário (desvantagem comercial), o resultado será negativo.

Um bom indicador que mede o efeito quantitativo global da proteção é dado pela evolução da taxa de abertura, expressa pela relação:

$$
\mathrm{TA}=\frac{\text { Importação }}{\text { PIB }}
$$

Estão incluídos neste indicador "os obstáculos não pautais, o que não isola o grau de protecionismo, pois a taxa de abertura é influenciada pela dimensão econômica do país em causa, e pela sua própria estrutura econômica" (MEDEIROS, 2003:I3I). Uma determinação da tendência da TA indicará, no entanto, a dinâmica das políticas protecionistas do país, podendo em certos casos indicar uma crescente falta de controle nas exportações.

No caso do Brasil, a evolução dos índices GAT e TA pode ser observada no gráfico a seguir, notando-se aumento de abertura, entretanto uma inflexão 
em 2002 da Taxa de Abertura poderá indicar uma inflexão da política expansionista do país ou, muito provavelmente, menor domínio nos circuitos de comercialização no exterior.

\section{GRÁFICO 3}

\section{EVOLUÇÃO DA ABERTURA EXTERNA TOTAL E TAXA DE} ABERTURA DO COMÉRCIO EXTERIOR BRASILEIRO

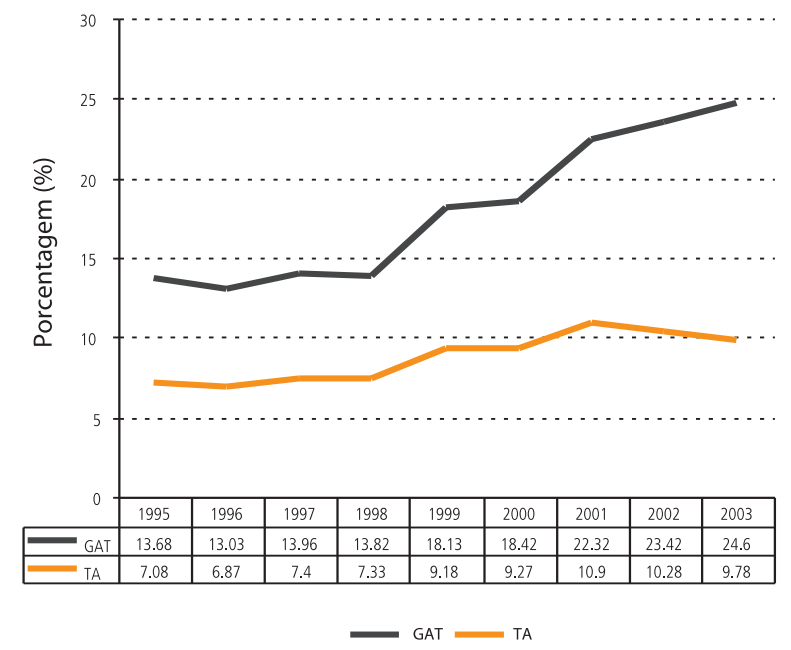

Fonte: Secex (2004).

\section{A METODOLOGIA DE ANÁLISE}

A análise da compatibilidade empresa/mercado de exportação, proposta neste artigo, será executada em várias fases:

I) Classificar com base no índice geral de Bela Balassa o grau de integração do Brasil, quer com os novos países ${ }^{8}$ (Io) da União Européia, quer com a União Européia (25).

2) Analisar a evolução dos produtos mais transacionados entre cada um dos países de maior integração com o Brasil, deduzidos no ponto anterior.

3) Analisar as vantagens comparativas reveladas (índice de vantagens comparativas reveladas) dos produtos de maior peso no total transacionado. 
4) Comparar os resultados com dados empresariais referentes ao porte de empresa (PMEs), e dedução do grau de compatibilidade setor/mercado, com base nos índices de vantagens comparativas reveladas e tradição das trocas comerciais no setor.

\section{APLICAÇÃO DA METODOLOGIA DE ANÁLISE AO CASO DO INTERCAMBIO COMERCIAL ENTRE O BRASIL E OS NOVOS PAÍsES NA UNIÃO EUROPÉA}

Pelo estudo deste caso, procuram-se compatibilizar setores de predominância industriais, em que a presença de pequenas e médias empresas industriais exportadoras, seja relevante com a sua possível penetração em vendas nos novos mercados criados pelo alargamento da União Européia para 25 países.

\section{QUADRO 3}

COBERTURA E ÍNDICE DE BELA BALASSA

\begin{tabular}{|c|c|c|c|c|c|c|c|c|c|c|c|c|}
\hline & \multicolumn{2}{|c|}{ EU (25) } & \multicolumn{2}{|c|}{ PL } & \multicolumn{2}{|c|}{$\mathrm{HU}$} & \multicolumn{2}{|c|}{ THC } & \multicolumn{2}{|c|}{ SLV } & \multicolumn{2}{|c|}{ SLK } \\
\hline & c & $\mathrm{IBB}_{\mathrm{a}}$ & c & $\mid \mathrm{BB} B_{\mathrm{a}}$ & C & $\mathrm{IBB}_{\mathrm{a}}$ & c & $\mathrm{IBB}_{\mathrm{a}}$ & c & $\mathrm{IBB}_{\mathrm{a}}$ & c & $\mathrm{IBB} \mathrm{B}_{\mathrm{a}}$ \\
\hline 1993 & 1,71 & 0,26 & 0,88 & 0,73 & 3,73 & 0,09 & 0,34 & 0,95 & 5,64 & 0,95 & 0,78 & 0,71 \\
\hline 1994 & 1,36 & 0,15 & 0,69 & 0,80 & 5,93 & $-0,07$ & 0,47 & 1,02 & 12,35 & 1,02 & 0,60 & 0,85 \\
\hline 1995 & 0,93 & $-0,04$ & 0,50 & 1,08 & 1,49 & $-0,37$ & 0,45 & 1,65 & 3,58 & 1,65 & 0,09 & 0,37 \\
\hline 1996 & 0,91 & $-0,04$ & 1,63 & 1,10 & 1,70 & 0,19 & 0,72 & 0,80 & 4,32 & 0,80 & 0,45 & 0,69 \\
\hline 1997 & 0,92 & $-0,04$ & 2,27 & 1,09 & 1,38 & 0,35 & 0,75 & 0,59 & 4,26 & 0,59 & 0,14 & 0,76 \\
\hline 1998 & 0,88 & $-0,07$ & 1,24 & 1,16 & 0,91 & 0,03 & 0,66 & 0,93 & 4,64 & 0,93 & 0,61 & 0,67 \\
\hline 1999 & 0,92 & $-0,04$ & 1,61 & 1,10 & 1,04 & 0,19 & 0,94 & 0,69 & 8,22 & 0,69 & 1,13 & 0,84 \\
\hline 2000 & 1,05 & 0,02 & 2,41 & 0,96 & 0,81 & 0,43 & 0,88 & 0,30 & 1,94 & 0,30 & 0,40 & 0,73 \\
\hline 2001 & 0,99 & $-0,01$ & 1,60 & 1,01 & 0,75 & 0,23 & 0,77 & 0,54 & 1,19 & 0,54 & 0,53 & 0,38 \\
\hline 2002 & 1,14 & 0,07 & 1,00 & 0,89 & 0,57 & 0,06 & 0,64 & 0,81 & 5,63 & 0,81 & 0,58 & 0,75 \\
\hline 2003 & 1,42 & 0,17 & 0,64 & 0,78 & 0,48 & $-0,10$ & 1,01 & 1,53 & 6,38 & 1,53 & 1,85 & 0,61 \\
\hline M & & & & & & & & & & & & \\
\hline IBB & & & & & & & & & & & & \\
\hline
\end{tabular}




\begin{tabular}{|c|c|c|c|c|c|c|c|c|c|c|}
\hline & \multicolumn{2}{|c|}{ EST } & \multicolumn{2}{|c|}{ LET } & \multicolumn{2}{|c|}{ LTH } & \multicolumn{2}{|c|}{ MLT } & \multicolumn{2}{|c|}{ CHP } \\
\hline & c & $\mathrm{IBB}_{\mathrm{a}}$ & C & $\mathrm{IBB}_{\mathrm{a}}$ & c & $\mathrm{IBB}_{\mathrm{a}}$ & c & $\mathrm{IBB}_{\mathrm{a}}$ & c & $\mathrm{IBB}_{\mathrm{a}}$ \\
\hline 1993 & 530,78 & 1,00 & 35,69 & 0,95 & 4,44 & 0,63 & 5,13 & 0,67 & 37,53 & 0,95 \\
\hline 1994 & 30,9 & 0,94 & 4,51 & 0,64 & 0,78 & $-0,12$ & 0,63 & $-0,23$ & 38,66 & 0,95 \\
\hline 1995 & 2,77 & 0,47 & 0,05 & $-0,91$ & 0,20 & $-0,66$ & 0,83 & $-0,10$ & 27,11 & 0,93 \\
\hline 1996 & 0,05 & $-0,90$ & 0,08 & $-0,84$ & 7,45 & 0,76 & 26,07 & 0,93 & 6,63 & 0,74 \\
\hline 1997 & 2,82 & 0,48 & 0,15 & $-0,74$ & 1,04 & 0,02 & 0,75 & $-0,14$ & 2,66 & 0,45 \\
\hline 1998 & 0,54 & $-0,30$ & 0,04 & $-0,92$ & 6,22 & 0,72 & 0,38 & $-0,45$ & 4,23 & 0,62 \\
\hline 1999 & 4,12 & 0,61 & 0,03 & $-0,95$ & 4,65 & 0,65 & 0,18 & $-0,69$ & 2,91 & 0,49 \\
\hline 2000 & 0,41 & $-0,42$ & 0,01 & $-0,99$ & 12,99 & 0,86 & 0,26 & $-0,59$ & 6,10 & 0,72 \\
\hline 2001 & 0,82 & $-0,10$ & 0,01 & $-0,99$ & 22,76 & 0,92 & 0,21 & $-0,65$ & 10,48 & 0,83 \\
\hline 2002 & 12,73 & 0,85 & 0,04 & $-0,93$ & 4,26 & 0,62 & 0,22 & $-0,64$ & 8,55 & 0,79 \\
\hline 2003 & 1,45 & 0,18 & 1,28 & 0,12 & 5,78 & 0,71 & 0,69 & $-0,18$ & 10,40 & 0,82 \\
\hline Média IBB & 0,2 & 255 & $-0,5$ & 505 & & 163 & & & 0,7 & \\
\hline
\end{tabular}

Fonte: Dados compostos pelo autor e Alice Web (2004).

\section{1) DETERMINAÇÃO DO ÍNDICE GERAL DE BELA BALASSA}

Numa primeira fase do processo determina-se a taxa de cobertura c, e o índice geral $\mathrm{IBB}_{\mathrm{a}}$ adaptado a cada um dos mercados em análise, com a finalidade de determinar o grau de especialização regional.

Pela análise do gráfico, comparando-se os níveis do Índice Geral de Bela Balassa com a média dos últimos in anos, conclui-se que os países em estudo com maior nível de integração são: Hungria, Eslovênia, Estônia, Lituânia e Chipre, pois o Índice Geral de Bela Balassa é superior à média da União Européia (25), refletindo maior especialização relativa exportadora do Brasil.

\section{2) ANÁLISE DOS PRODUTOS MAIS TRANSACIONADOS COM OS PAÍSES INDICADOS}

A análise histórica das exportações brasileiras, para os países indicados, dos produtos com maior peso nas exportações, classificados pelos números do 
capítulo do Sistema Harmonizado de Designação e Codificação Mercadorias $(\mathrm{SH})^{9}$ - Quadro 4 -, permite avaliar a tradição exportadora setorialmente (setores CNAE).

\section{QUADRO 4}

\section{EXPORTAÇŌES BRASILEIRAS (SETORES MAIS REPRESENTATIVOS)}

\section{Classificação produtos (SH)}

\begin{tabular}{|l|r|r|r|r|r|r|r|r|r|r|r|r|r|r|r|}
\hline & $\%(1)$ & $\%(2)$ & $\%(3)$ & 02 & 09 & 10 & 21 & 23 & 26 & 44 & 47 & 64 & 72 & 84 & 88 \\
\hline Polônia & 5,0 & 5,2 & 9,3 & $\mathrm{X}$ & & $\mathrm{X}$ & & & $\mathrm{X}$ & & & & & & $\mathrm{X}$ \\
\hline Chipre & 10,3 & 27,1 & 72,4 & $\mathrm{X}$ & $\mathrm{X}$ & & & & & & & $\mathrm{X}$ & & $\mathrm{X}$ & \\
\hline Lituânia & 6,2 & 6,5 & 12,3 & & & & $\mathrm{X}$ & & & $\mathrm{X}$ & & & $\mathrm{X}$ & $\mathrm{X}$ & \\
\hline Eslovênia & 2,9 & 8,9 & 35,5 & & $\mathrm{X}$ & $\mathrm{X}$ & & $\mathrm{X}$ & & & $\mathrm{X}$ & & & & \\
\hline Estônia & 11,2 & 11,7 & 22,5 & & & & & & & $\mathrm{X}$ & & & $\mathrm{X}$ & & \\
\hline Hungria & 9,0 & 10,3 & 10,7 & $\mathrm{X}$ & $\mathrm{X}$ & & & & & & & $\mathrm{X}$ & & $\mathrm{X}$ & \\
\hline
\end{tabular}

Nota: os valores relacionados às porcentagens (I) e (2) se referem à média dos anos $1998-2003$ e os relacionados à porcentagem (I), ao ano 2003.

I) (\%) das classes 44-64-84 no total das exportações (média dos anos i998 $-2003)$.

2) (\%) das classes $44-64-84$ no total das exportações de manufaturados (SH cap. acima $\mathrm{i} 6$ ).

3) (\%) das classes $44-64-84$ no total das exportações de manufaturados, exceto as duas classes mais exportadas no país.

Fonte: Aliceweb e dados compostos pelo autor.

Um escrutínio nos resultados do Quadro 4 permite definir quais os setores de transformação com maior peso no intercâmbio comercial e deduzir desse modo os elementos do Quadro 5, que refletem as empresas industriais exportadoras, em cada setor (CNAE) deduzido.

Outra conclusão possível é a constatação, por um lado, do elevado percentual, e a não-concentração em classe específica de manufaturados na estrutura de exportação para a Polônia e Hungria, e, por outro, a elevada especialização exportadora em produtos de vantagens comparativas reveladas para o Chipre. Estas poderão ser algumas das diretrizes válidas para promoção setorial de exportações. 


\section{QUADRO}

NoDE EMPRESAS INDUSTRIAIS EXPORTADORAS E VALOR EXPORTADO SEGUNDO SETOR DE ATIVIDADE

\begin{tabular}{|c|c|c|c|c|c|c|c|c|c|c|c|c|c|c|c|}
\hline \multirow{2}{*}{ Setor CNAE } & \multicolumn{5}{|c|}{1997} & \multicolumn{5}{|c|}{1998} & \multicolumn{5}{|c|}{1999} \\
\hline & $n^{0}$ & $\%$ & valor & $\%$ & média & $n^{0}$ & $\%$ & valor & $\%$ & média & $n^{0}$ & $\%$ & valor & $\%$ & média \\
\hline $\begin{array}{l}\text { Fabricação de produtos } \\
\text { alimentícios e bebidas }\end{array}$ & 763 & 8,0 & 9.272 & 21,1 & 12,15 & 751 & 7,8 & 8.748 & 20,4 & 11,65 & 818 & 8,0 & 8.495 & 20,7 & 10,39 \\
\hline $\begin{array}{l}\text { Preparação e fabricação } \\
\text { de couros e calçados }\end{array}$ & 776 & 8,1 & 2.178 & 5,0 & 2,81 & 749 & 7,7 & 1.821 & 4,2 & 2,43 & 778 & 7,6 & 1.628 & 4,0 & 2,09 \\
\hline $\begin{array}{l}\text { Fabricação de produtos } \\
\text { de madeira }\end{array}$ & 651 & 6,8 & 1.014 & 2,3 & 1,56 & 687 & 7,1 & 888 & 2,1 & 1,29 & 829 & 8,1 & 1.133 & 2,8 & 1,37 \\
\hline Metalurgia básica & 301 & 3,1 & 5.604 & 12,8 & 18,62 & 307 & 3,2 & 5.270 & 12,3 & 17,17 & 296 & 2,9 & 5.235 & 12,8 & 17,69 \\
\hline $\begin{array}{l}\text { Fabricação de máquinas } \\
\text { e equipamentos }\end{array}$ & 1.244 & 13,0 & 2.846 & 6,5 & 2,29 & 1.268 & 13,1 & 2.609 & 6,1 & 2,06 & 1.316 & 12,9 & 2.118 & 5,2 & 1,61 \\
\hline
\end{tabular}

$\begin{array}{lllllll}\text { total geral (no absoluto) } & 9.578 & 43.860 & 9.677 & 42.978 & 10.229 & 40.974\end{array}$

\begin{tabular}{|c|c|c|c|c|c|c|c|c|c|c|}
\hline \multirow{2}{*}{ Setor CNAE } & \multicolumn{5}{|c|}{2000} & \multicolumn{5}{|c|}{2001} \\
\hline & no & $\%$ & valor & $\%$ & média & $n^{0}$ & $\%$ & valor & $\%$ & média \\
\hline $\begin{array}{l}\text { Fabricação de produtos } \\
\text { alimentícios e bebidas }\end{array}$ & 817 & 7,5 & 8.553 & 17,9 & 10,47 & 856 & 7,8 & 10.253 & 20,8 & 11,98 \\
\hline $\begin{array}{l}\text { Preparação e fabricação } \\
\text { de couros e calçados }\end{array}$ & 794 & 7,3 & 1.944 & 4,1 & 2,45 & 847 & 7,7 & 2.098 & 4,3 & 2,48 \\
\hline $\begin{array}{l}\text { Fabricação de produtos } \\
\text { de madeira }\end{array}$ & 910 & 8,4 & 1.190 & 2,5 & 1,31 & 893 & 8,1 & 1.168 & 2,4 & 1,31 \\
\hline Metalurgia básica & 299 & 2,8 & 6.041 & 12,6 & 20,20 & 304 & 2,8 & 5.167 & 10,5 & 17,00 \\
\hline $\begin{array}{l}\text { Fabricação de máquinas } \\
\text { e equipamentos }\end{array}$ & 1.316 & 12,1 & 2.291 & 4,8 & 1,74 & 1.288 & 12 & 2.288 & 4,6 & 1,78 \\
\hline
\end{tabular}

total geral (nº absoluto) $\quad 10.836 \quad 47.840 \quad 11.031 \quad 49.223$

- valores em US\$ milhões

- \% do total

- média - valor exportado por empresa em milhões US\$

- não foram consideradas as atividades de fabrico de aeronaves (capítulo 88) e extração de minério de ferro (capítulo 26), por serem típicas de empresas de grande porte

Fonte: Funcex (www.funcex.gov.br) cit. Secex/MDIC e IBGE. 
A estrutura anteriormente demonstrada conduz à conclusão de que a exportação dos setores de preparação e fabricação de couros e calçados, fabricação de produtos de madeira, de máquinas, aparelhos e materiais elétricos representa áreas predominantemente de pequenas e médias empresas, motivo pelo qual este estudo será baseado nelas.

\begin{tabular}{l|l|c}
\hline Setor do CNAE & Designação do SH & No cap. (SH) \\
\hline $\begin{array}{l}\text { Fabricação de } \\
\text { produtos de madeira }\end{array}$ & Madeira, carvão vegetal e obras de madeira & $\mathbf{4 4}$ \\
\hline $\begin{array}{l}\text { Preparação e fabricação } \\
\text { de couros e calçados }\end{array}$ & $\begin{array}{l}\text { Calçados, polainas e artefatos semelhantes } \\
\text { e suas partes }\end{array}$ & $\mathbf{6 4}$ \\
\hline $\begin{array}{l}\text { Fabricação de } \\
\text { máquinas e equipamentos }\end{array}$ & $\begin{array}{l}\text { Reatores nucleares, caldeiras, máquinas, } \\
\text { aparelhos e instrumentos mecânicos e suas partes }\end{array}$ & $\mathbf{8 4}$ \\
\hline
\end{tabular}

A análise histórica da performance desses produtos (classes 44, 64 e 84) nos seis mercados em estudo conclui com os seguintes elementos:

\section{Exportação capítulo 44}

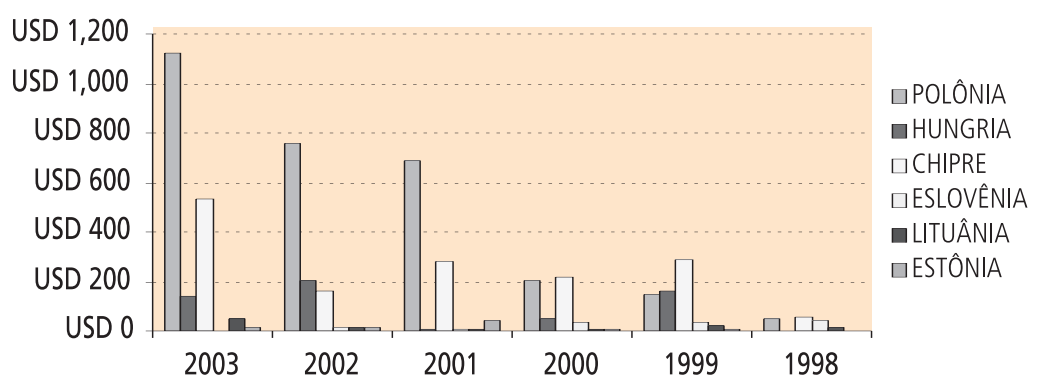

Exportação capítulo 64

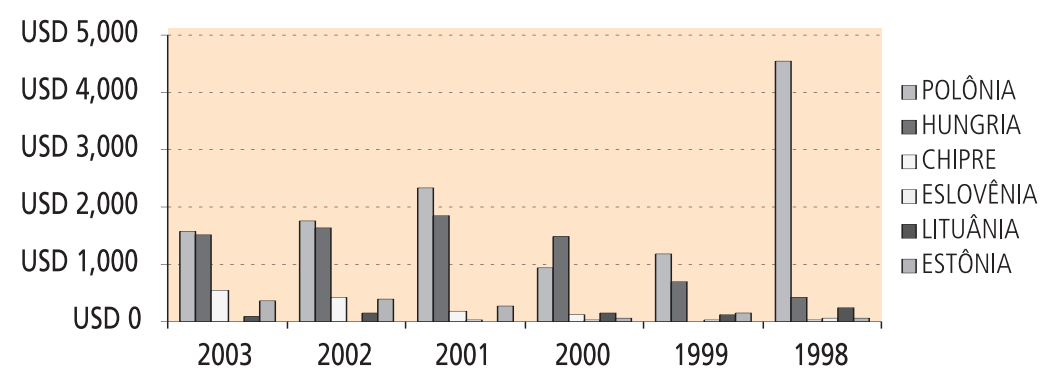


Verifica-se pelos gráficos que as exportações nessas classes tenderam a diminuir nos últimos anos, com exceção do capítulo 44 - madeira e obras em madeira -, que tem apresentado aumento, e de algum pico exportador (Letônia - cap. 84), que poderá ser analisado em pormenor.

\section{Exportação capítulo 84}

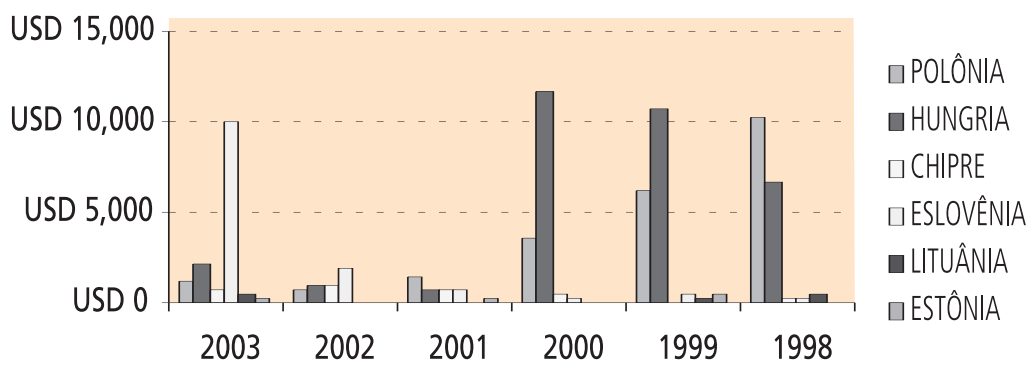

\section{3) ANÁLISE DAS VANTAGENS COMPARATIVAS REVELADAS}

Uma análise das vantagens comparativas reveladas para os setores de atividade considerados, ao longo dos anos I998 - 2003, conduz aos resultados do Quadro 6:

\section{QUADRO 6}

\begin{tabular}{l|c|c|c|c|c|c}
\hline \multirow{2}{*}{ Discriminação } & \multicolumn{2}{|c|}{1998} & \multicolumn{2}{c|}{1999} & \multicolumn{2}{c}{2000} \\
\cline { 2 - 7 } & IVCR & IVCR $_{2}$ & IVCR & IVCR $_{2}$ & IVCR & IVCR $_{2}$ \\
\hline $\begin{array}{l}\text { Madeira e obras } \\
\text { em madeira 44 }\end{array}$ & 89,21 & 12,24 & 93,47 & 25,20 & 91,69 & 21,47 \\
\hline $\begin{array}{l}\text { Calçados 64 } \\
\text { Máquinas e } \\
\begin{array}{l}\text { equipamentos } \\
\text { mecânicos 84 }\end{array}\end{array}$ & 90,82 & 13,64 & 93,77 & 26,23 & 95,20 & 35,83 \\
\hline
\end{tabular}

Cobertura

0,886
Cobertura

0,974
Cobertura

0,987 
QUADRO 6 (CONTINUAÇÃO)

\begin{tabular}{l|c|c|c|c|c|c}
\hline \multirow{2}{*}{ Discriminação } & \multicolumn{2}{|c|}{1998} & \multicolumn{2}{c|}{1999} & \multicolumn{2}{c}{2000} \\
\cline { 2 - 7 } & IVCR & IVCR $_{2}$ & IVCR & IVCR $_{2}$ & IVCR & IVCR $_{2}$ \\
\hline $\begin{array}{l}\text { Madeira e obras } \\
\text { em madeira 44 }\end{array}$ & 90,69 & 26,26 & 82,85 & 30,86 & 74,06 & 23,62 \\
\hline Calçados 64 & 91,60 & 30,36 & 81,78 & 25,20 & 73,52 & 21,42 \\
\hline $\begin{array}{l}\text { Máquinas e } \\
\text { equipamentos } \\
\text { mecânicos 84 }\end{array}$ & $(41,42)$ & 0,42 & $(44,04)$ & 0,40 & $(36,59)$ & 0,48 \\
\hline
\end{tabular}

\begin{tabular}{|c|c|c|c|}
\hline & Cobertura & Cobertura & Cobertura \\
\hline $\begin{array}{l}\text { Balança comercial } \\
\text { (milhões FOB) }\end{array}$ & 1,048 & 1,228 & 1,514 \\
\hline
\end{tabular}

\section{4) DEDUÇÃO DO GRAU DE COMPATIBILIDADE SETOR/MERCADO}

A dedução do grau de compatibilidade setor atividade/mercado para empresas produtoras/exportadoras de pequena e média dimensão, atendendo à anterior metodologia, será analisada pelos fatores deduzidos:

I. IVCR.

II. Tradição exportadora (TR).

Por meio de apresentação matricial - Quadro $7^{10}$ - executada com base nos fatores IVCR e TR, podem ser representados os diferentes mercados em análise, com base nas variáveis "Vantagem Comparativa Revelada", definida pela relação IVCR/TC (taxa de cobertura de referência ao produto representado pelo capítulo $\mathrm{SH})$, e "Tradição Exportadora", definida pela tangente da reta de tendência representativa da evolução das exportações observadas nos últimos anos. 


\section{QUADRO 7}

\begin{tabular}{|c|c|c|c|c|}
\hline \multirow{2}{*}{\multicolumn{2}{|c|}{$\begin{array}{l}\text { Produto Cl. (SH) } \\
\text { Brasil / País importador }\end{array}$}} & \multicolumn{3}{|c|}{ Vantagens Comparativas Reveladas } \\
\hline & & Elevada (4) & Normal (5) & Baixa (6) \\
\hline \multirow{3}{*}{ 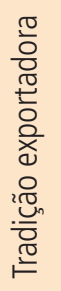 } & Crescimento (1) & 1 & (2) & 3 \\
\hline & Manutenção (2) & (4) & 5 & 6 \\
\hline & Declínio (3) & 7 & 8 & 9 \\
\hline
\end{tabular}

I) inclinação da reta de tendência positiva maior que $20^{\circ}$

2) inclinação da reta de tendência entre $\pm 20^{\circ}$

3) inclinação da reta de tendência negativa maior que $20^{\circ}$

4) $\operatorname{ICVR}_{2}$ (média dos últimos $n$ anos) $\mathrm{X}$ vezes ${ }^{11}$ maior do que a cobertura (média dos últimos $n$ anos)

5) Valor de $\operatorname{ICVR}_{2}$ (média dos últimos $n$ anos) entre $\pm X$ do que a cobertura (média dos últimos $n$ anos)

6) $\operatorname{ICVR}_{2}$ (média dos últimos $n$ anos) menor do que a cobertura (média dos últimos $n$ anos)

A análise dessa matriz - Quadro 7 - pressupõe que para mercados situados em (1) deverão ser conduzidos esforços importantes, quer empresariais, quer de promoção, para intensificar as trocas comerciais. Para os quadrantes 2 a promoção conjugada com o esforço governamental deve ser efetuada para intensificar o comércio. No quadrante (4, o foco será no esforço interno de reconversão, modernização de processos e equipamentos. Já nos quadrantes (3, (5) e $\boldsymbol{7}$, empresas comerciais exportadoras devem ser incentivadas a atuar em colaboração com o setor exportador em análise.

\section{CONCLUSÕES}

A análise cruzada - trade-off - entre as vantagens comparativas reveladas e a tradição exportadora direcionará o processo decisório, sempre que determinado 
setor de atividade (indústria ou setor industrial) pretenda se desenvolver em mercados alternativos, como base das suas estratégias de internacionalização empresarial. O desenvolvimento da metodologia proposta permite ainda deduzir o grau de influência desejável para o recurso "orientação ao mercado", aqui caracterizado por "controle de mercado", na interferência de empresas do tipo comerciais exportadoras ou de tradings, no processo de internacionalização das empresas industriais. Também a introdução da variável "tradição exportadora" possibilita analisar e decidir sobre o aproveitamento em sinergias de promoção empresariais ou no direcionamento de políticas públicas comerciais que tenham por objetivo fomentar a internacionalização empresarial.

Baseada nesta metodologia, cada indústria ou setor de atividade deverá analisar a sua compatibilidade com determinado mercado, que a priori se mostre atrativo, devendo por isso condicionar a sua ação, não somente àquele apelo (atratividade versus compatibilidade), mas também à tradição exportadora e real capacidade do mercado.

Já os poderes públicos poderão utilizar esta metodologia na definição de políticas de promoção e fomento de exportação envolvendo pequenas e médias empresas industriais e atender à representação matricial no direcionamento de suas políticas de desenvolvimento do potencial exportador das PMEs e/ou de reajustamento na qualificação da matriz exportadora do país.

\section{REFERÊNCIAS}

ACS, J. Z. Are small firms important? Their role and impact. Boston: Kluwer Academic Publishers, I999.

BALASSA, B. Teoria de integração econômica. Lisboa: Clássica Editora, I964.

BNDES. Classificação de porte de empresa. Disponível em: <www.bndes.gov.br/clientes/porte/porte.asp>. Acesso em: 26 maio 2004 .

ESHIMA, Y. Impact of public policy on innovative SMEs in Japan. Journal of Small Business Management, n. 4I (I), 2003.

FERRARO, C.; GATTO F. Las Pymes en el Mercosur definiciones y primeras estimaciones. Documento de Trabajo n. 37. Buenos Aires: CFl- CEPAL, I993. . Internacionalízación de las pequeñas y medianas empresas argentinas, exportación y modalidades de cooperación internacional, LC/BUE/R, 209. Buenos Aires: CEPAL, I995.

GATTO, F. Los desafios de la internacionalización y el Mercosur para las Pymes argentinas. Documento apresentado no Seminário "Descentralización y Desarrollo", Agencia Española de Cooperación Internacional, Santiago de Chile, Chile, I994.

GREENAWAY, D.; MILNER, C. What have we learned from a generation's research on intraindustry trade? Research paper 2003/44, University of Nottingham, 2003.

GRUBEL, H. G., LLOYD, P. J. Intra-industry trade: the theory and measurement of international trade in differentiated products. London: Macmillan, I975. 
GUIMARÃES, E. P. Política de exportação brasileira para as pequenas e médias empresas. In: PINHEIRO, A; MARKWALD, R.; PEREIRA, L. V. O desafio das exportações. Rio de Janeiro: BNDES, 2002.

HELPMAN, E. International trade in the presence of product differentiation, economies of scale and monopolistic competition: a Chamberlin-Heckscher-Ohlin approach. Journal of International Economics, II:305-40, I98I.

HOGAN, P., KEESING, D.; SINGER, A. The role of support services in expanding manufactured exports in developing countries. EDI Seminar Series, Economic Development Institute of the World Bank. Washington DC, I99I.

HUNT, S. D. A general theory of competition: resources, competences, productivity, economic growth. Thousand Oaks: Sage, 2000.

. Resource-advantage theory and Austrian economics: toward an Austrian theory of competition? Austrian Scholars Conference. Ludwig von Mises Institute, March I5-I6, 2002.

. MORGAN, R. M. The comparative advantage theory of competition. Journal of Marketing, vol. 59, p. I-I5, april, I995.

KAPLINSKY, R.; READ J. Integrating SME's in global value chains - Towards partnership for development. Vienna: UNIDO, 200I.

KRUGMAN, P. R. Scale economics, product differentiations, and the pattern of trade. American Economic Review, I980.

KRUGMAN, P. R.; OBSTFEELD, M. Economia internacional: teoria e política. 5. ed. São Paulo: Makrou Books, 200I.

LANCASTER, K. Intra-industry trade under perfect monopolistic competition. Journal of International Economics I0:I5I-75, I980.

LEMOS, C. Innovation and industrial policies for small firms in Brazil. $4^{\text {th }}$ International Conference on Technology Policy and Innovation, Curitiba, 2000.

MAIA, J. M. Economia internacional e comércio exterior. São Paulo: Atlas, 2003.

MEDEIROS, E. R. Economia internacional. Lisboa: Instituto Superior de Ciências Sociais e Políticas, 2003 .

NOTHDURFT, W. Going global. How Europe helps small firms export. German Marshall Fund of United States Book. Washington: The Brookings Institution, I992.

PINHEIRO, A. C.; MOREIRA, M. M. O perfil dos exportadores brasileiros de manufaturados nos anos 90 - Quais as implicações de política. Texto para discussão n. 80, BNDES, 2000.

SECRETARIA DA RECEITA FEDERAL. Disponível em: <www.receita.fazenda.gov.br/Legislacao/LegisAssunto/SisHar.htm>. Acesso em: 26 de maio de 2004 .

TR A MITAÇ Ã O

Recebido em 30/05/2004

Aprovado em 23/10/2004 